\title{
The role of intestinal flora in autism and nutritional approaches
}

\author{
Aslı Melike Ekmekçi1 (iD, Oytun Erbaş ${ }^{1,2}$ (D) \\ ${ }^{1}$ Institute of Experimental Medicine, Gebze-Kocaeli, Turkey \\ ${ }^{2}$ Department of Physiology, Medical Faculty of Demiroğlu Bilim University, Istanbul, Turkey
}

\begin{abstract}
Autism spectrum disorder (ASD) is a social behavior disorder and awareness on ASD has been increasing nowadays. Social deficiencies and repetitive movements constitute the symptoms of ASD occurring in childhood. As there is no biological marker in autism, parental and clinician approaches are based on diagnosis. Genetic and environmental factors play a role in autism, and its prevalence has been increasing in recent years. The process and amount of exposure to environmental factors create differences in the cause of autism. Although it is unclear yet whether autism is a cause or result, impaired intestinal flora is among the symptoms of autism. Factors such as nutrition approaches and perinatal factors have been thought to play a role in intestinal flora dysbiosis. Metabolites that cross the blood-brain barrier in the intestinal flora dysbiosis can cause morphological changes in the hippocampus in the brain. Various dietary approaches and fecal microbiota transplantation have become candidates for autism treatment methods to improve the deteriorated flora. In this review, we discuss the effects of therapeutic nutritional approaches and fecal transplantation by examining the relationship between ASD and intestinal flora.
\end{abstract}

Keywords: Autism spectrum disorder, intestinal flora, nutrition

Autism spectrum disorder (ASD) is a behavioral disorder characterized by language and social deficiencies that occur in childhood. Repetitive behaviors, obsessions, and communication difficulties are observed in autism. Autism was first described in the literature by the American psychiatrist Leo Kanner as "early childhood schizophrenia" in 1943. ${ }^{[1]}$ According to the National Health Statistics Report published in the United States, the prevalence of autism, which was 1:86 in 2007, increased to $1: 50$ in 2012. ${ }^{[2]}$ Factors such as increased awareness of physicians and parents, differences in diagnostic criteria, widespread use of screening scales and keeping accurate data are effective. ${ }^{[3]}$

Genetic and environmental factors play a role in the pathogenesis of ASD. Although singlegene polymorphisms are effective in autism, autism does not occur without environmental factors. Among the major causes of autism are heavy metals, antibiotics and chemical toxic substances. Other causes include diet, infections (Morbilli/measles, human herpesvirus 6/HHV6, cytomegalovirus/CMV, Streptococci, Clostridia, Borrelia, and Candida spp.), mode of delivery, oxygen deficiency during delivery and after delivery, and differences in cerebral blood supply. Autism is seen in children who cannot cope with environmental problems due to their genetic tendencies, as a result of a series of mechanisms. Therefore, these environmental factors in autism, the intestinal flora (microbiota) is differentiated. Differentiated microbiota lead to gastrointestinal symptoms in individuals with autism.

In this review, we discuss the effects of microbiota, the effects of microbiota on autism, nutritional approaches, and the effects of fecal microbiota transplantation (FMT) on autism as an alternative treatment method. ${ }^{[1,4]}$

Correspondence: Aslı Melike Ekmekçi. Deneysel Tıp Enstitüsü, 41470 Gebze-Kocaeli, Türkiye. 


\section{INTESTINAL FLORA (MICROBIOTA)}

The intestinal microbiota contains about 3 million genes, or 150 times more genes than the human genome. ${ }^{[5]}$ Colonization in the human body first begins with exposure to the mother's vaginal microbiota during delivery. The intestinal microbiota of infants delivered vaginally is similar to the vaginal microbiota of their mothers dominated by Lactobacillus, Prevotella or Sneathia spp., the intestinal microbiota of infants delivered by cesarean section is Staphylococcus, Corynebacterium and Propionibacterium spp., and observed to be similar to the skin microbiota of mothers. ${ }^{[6]}$

There are two dominant types of bacteria in the human microbiota: Bacteroidetes and Firmicutes filum. Proteobacteria, Actinobacteria, Fusobacteria and Verrucomicrobia phylum are less common. ${ }^{[7]}$ The microbiome in the first meconium of mice is not sterile, indicating that the microbiome colonizes the infant intestines before birth. ${ }^{[8]}$ Subsequent interactions with nutrition and the environment result in increased intestinal flora diversity. Microbial diversity differs among individuals in terms of diet, hygiene, social behavior, vaccination and genetic factors. ${ }^{[6]}$ Studies have revealed significantly more clostridia and ruminococcus in the stool of the autistic group with gastrointestinal (GI) symptoms. ${ }^{[9]}$ Hippocampal neurodevelopment was altered in two groups of mice whose microbiota was altered with germ-free antibiotics and consequently spatial and object recognition was impaired. ${ }^{[10]}$

\section{AUTISM - MICROBIOTA}

A potential connection between microbiota and ASD has been suggested over two decades ago. Recent studies suggest that autism is a disease scene that begins in the gastrointestinal system and shows results in the brain. First, oral vancomycin therapy provides a short-term benefit in a small group of children with ASD, and later, intestinal bacteria research in children with ASD revealed differences compared to the control group. Since then, numerous studies from various cohorts have reported that the microbiome profiles of ASD individuals, particularly those with comorbid gastrointestinal dysfunction, differ from control groups. More than half of the children with autism have gastrointestinal problems. In addition, almost all children with autism do not have a normal intestinal flora. ${ }^{[1,11,12]}$ In a metaanalysis of 144 studies, constipation was found to be in 4.3 to $45.5 \%$, diarrhea in 2.3 to $75.6 \%$, and more than one symptom in 4.2 to $96.8 \%$. ${ }^{[13]}$

Abnormal intestinal functions in autism affect the brain due to increased permeability. The gutbrain axis, which is a communication pathway between the gut and the brain, has been accepted as a two-way communication system. The gutbrain axis plays a role in the pathogenesis of ASD. Intestinal microbiota affects brain function through the neuro-endocrine, neuro-immune, autonomic nervous systems, and toxin production of the microbiota. ${ }^{[14]}$ Stool samples that obtained from children with ASD revealed higher levels of Clostridium histolyticum compared to samples from healthy unrelated children. In addition, intestinal dysbiosis has occurred in children with autism. ${ }^{[15]}$ The main factor underlying the relationship between $\mathrm{ASD}$ and the intestine is the increased permeability of the intestinal tract of individuals with ASD, and this is referred to as leaky gut ${ }^{[16]}$ According to the leaky gut hypothesis, the permeability of the mucosal barrier increased with reduced tight-junction activity. Since the function of intestinal cells is impaired, vitamins, minerals and other nutrients related to carrier proteins cannot pass into the blood sufficiently. Therefore, related symptoms of inadequacy occur. It has been suggested that gliadamorphine and casomorphine, which are partial digestive products of harmful substances produced by microorganisms such as gliadin and casein, cross the intestinal barrier and affect the functions of the central nervous system (CNS) by passing to the blood and then to the brain. These opioid proteins cause behavioral changes in the brain and gut, constipation, bloating and diarrhea. Morphine poisoning might be the most likely reason why children with autism are resistant to pain. ${ }^{[17,18]}$ Although it is not clear whether the impaired microbiota is the cause or the result of autism yet, metabolites have crossed the bloodbrain barrier and formed the gut brain axis as a result of the increased permeable flora.

\section{AUTISM - MICROBIOTA - ANIMAL MODELS}

Epidemiological studies have identified exposure to infection in the neonatal period as a 
risk factor for a number of neurological disorders such as autism and schizophrenia. Immunogen activation (MIA) is performed with propionic acid (PPA), valproic acid (VPA), lipopolysaccharide (LPS) or polycytidylic acid: (i.e. poly(I:C)) to create a model of autism in mice. Autism-like behaviors, including impaired communication, were observed particularly in male rats by administering PPA $\mathrm{mg} / \mathrm{kg}$ for three days or giving LPS $100 \mu \mathrm{g} / \mathrm{kg}$ intraperitoneally to create a rodent model with autistic characteristics. In additional method, autism symptoms occur when VPA is dissolved in saline by intraperitoneal injection and administered $600 \mathrm{mg} / \mathrm{kg}$ on Day 12.5 of embryonic pregnancy. Genes related to social behavior were found to be decreased in the hippocampus of these rats. ${ }^{[19-22]}$ When the mice were examined behaviorally with the Dyadic social interaction test, they showed increased repetitive behavior, diarrhea, decreased sociability and decreased mobility compared to the control groups.

When ASD human intestinal microbiota donors were transplanted into germ-free mice, autistic behaviors were induced. These behavioral disorders caused by ASD microbiota were more prominent in male mice. ${ }^{[19]}$ Studies have found that the blood-brain barriers of mice known as germfree are permeable. Morphological differences were observed in these mice, particularly in the amygdala and hippocampus. Intestinal microbiota is involved in neuronal communication with molecules such as dopamine, glutamate, and serotonin, which are effective in key pathways such as citrate cycle, synaptic long-acting potential, c-AMP mediated signaling and these systems affect social skills in animals. ${ }^{[23]}$

\section{AUTISM - PERINATAL FACTORS}

According to academic studies, the diversity of microbiota that occurs in the perinatal period has a lifelong effect on natural killer cells. ${ }^{[24]}$ The maternal immune activation model that causes neuroinflammation in the brain developing in ASD pathogenesis causes long-term changes in the microbiota and behavioral disorders in young animals. ${ }^{[20,25]}$ During development, in addition to fatty acids and sugars, satiety hormones such as insulin and leptin and low-grade inflammatory factors caused by obesity may play a role in the deterioration of the neuroendocrine system and in the neuronal circuits that regulate behavior in offspring. These factors cross the placenta, affect the development of the neuronal circuits of the offspring, impair the behavioral phenotype and increase the risk of developing ASD. ${ }^{[26]} \mathrm{A}$ study found that mothers whose pre-pregnancy weight is over $90 \mathrm{~kg}$ are more likely to develop autistic children. Therefore, a clear relationship can be established between obesity during pregnancy and ASD formation in offspring. Factors such as the mother's age, diet, mode of delivery and environment and stress have been evaluated as perinatal factors in autism by affecting the microbiota-gut-brain axis. ${ }^{[27]}$

\section{AUTISM - GUT-BRAIN AXIS}

The interaction between the intestinal flora and the CNS works bidirectionally with a system called the "Gut-Brain Axis". This communication network is formed by the CNS, brain and spinal cord, autonomic nervous system, enteric nervous system, hypothalamic pituitary adrenal (HPA) axis. ${ }^{[28]}$ The HPA is a part of the limbic system and is an important region of the brain in autism, mainly related to memory and emotional behavior. The vagus nerve can sense microbiota metabolites through sensory fibers and transmit them from the intestine to the CNS. Short chain fatty acids produced by microorganisms in the microbiota activate vagal sensory fibers. Propionate, in particular, from the accumulation of short-chain fatty acids, has been shown to have broad effects on the CNS and cause developmental delays or seizures. ${ }^{[29]}$ Toll-like receptors are located on vagal sensory fibers and these fibers can detect bacterial products such as lipopolysaccharide and activate the brain. Microorganisms affect neurotransmitter production by vagus innervation. Microorganisms may affect the levels of neurotransmitters such as gamma-aminobutyric acid, serotonin, norepinephrine and dopamine. ${ }^{[30]}$ It has been suggested that abnormal microbiota formed as a result of these factors impairs the immune system by affecting lymphocyte migration and differentiation in the gastrointestinal system. Microorganisms can cause disruption of the intestinal epithelium layer by stimulating the release of various cytokines and chemokines. Allergies can be observed as a result of increased immune activation against these antigens that enter the systemic circulation. ${ }^{[30,31]}$ Environmental stress and high pro-inflammatory cytokines 
activate this system, which in turn stimulates the secretion of adrenocorticotropic hormone (ACTH) from the pituitary gland through the stimulation of corticotropin releasing factor (CRF) from the hypothalamus and induces cortisol release from the adrenal glands. Cortisol is an important stress hormone that affects many human organs, including the brain. Therefore, cells such as both neural and hormonal lines of communication, immune cells (astrocytes, neuroglia), epithelial cells, enteric neurons, smooth muscle cells, Cajal's interstitial cells, and enterochromaffin cells can influence the activities of intestinal cells. ${ }^{[32]}$ Consequently, these communication systems between the intestinal microbiota and the brain are important pathways for autism. The disrupted flora lead differentiation in the hippocampus region of the brain through the bidirectional system between the brain and the intestine. Dysbiosis in the microbiota can also activate immune cells by activating immune functions. More studies are needed to improve these system activities between the gut and the brain in autism.

\section{NUTRITIONAL APPROACHES IN AUTISM}

Most children with ASD experience anxiety about nutrition. ${ }^{[33]}$ Children with ASD have more food allergies than other children. ${ }^{[4,35]}$ Selective eating, food refusal, food obsession is common problem eating behaviors reported in children with ASD. ${ }^{[36]}$ In addition to rejecting fruits and vegetables, starches, snacks and processed foods are the most common choices in children with ASD. Increased consumption of snacks and foods high in calories can lead to excessive weight gain. ${ }^{[37,38]}$ Diet has been suggested as a therapeutic measure for ASD symptoms. During the diagnosis of ASD, some dietary interventions have been tried as a treatment. ${ }^{[39,40]}$ A number of nutritional strategies have been explored to treat behavioral disorders and accompanying intestinal distress, including gluten/casein-free diets, ketogenic diets (KDs) or probiotic supplementation. Certain diets (e.g. gluten/casein-free diet, ketogenic diets) have been observed to help alleviate symptoms associated with ASD. ${ }^{[40-42]}$ For the right interventions, detailed diet and supplements should be evaluated and personalized diet therapies should be prepared by a trained dietician. It is concluded that more research is needed to make general recommendations about diets that can be a treatment method for ASD.

\section{GLUTEN-FREE/CASEIN-FREE DIET TREATMENT IN AUTISM}

When gluten and casein proteins are not fully digested in individuals with autism, it may lead to behavioral disorders. It has been hypothesized that abnormal metabolism of these two proteins may result in excess opioid activity in the CNS. Therefore, eliminating gluten means eliminating wheat, oats, barley or rye - all flours, breads, breadcrumbs, pasta, pastries and others. The casein-free diet means no dairy products such as breast milk, yoghurt, cheese, butter, cream or ice cream are restricted. ${ }^{[43-45]}$ It has been observed that most individuals with autism are addicted to foods containing gluten and casein. It was thought that caseinomorphine and glutenomorphine compounds that cross the blood-brain barrier without being digested cause morphine addiction. In a study, this diet was applied to 120 individuals with schizophrenia and 149 autism. A total of $87 \%$ of children with autism were found to have high titer immunoglobuline G gliadin and 30\% high titer trans indolyl acrylic glycine antibodies against gluten or casein. ${ }^{[45]}$

Results of gluten-free and casein-free nutrition were tested in children with autism $(n=30)$ and positive effects on physiological activity, behavioral problems like autism symptoms and no significantly difference was. ${ }^{[46]}$ Since data supporting or refuting gluten-free and casein-free nutrition in ASD is still insufficient, further longterm randomized controlled studies are needed.

\section{KETOGENIC DIET THERAPY IN AUTISM}

Ketogenic diet is a high-fat, low-carbohydrate diet and is an effective treatment for epileptic patients who fail to respond to anticonvulsant medication. Recent studies have revealed that $\mathrm{KD}$ application has positive effects on reducing ASD symptoms. A KD during the period of six months and a control diet for two weeks were applied to 30 ASD children without epilepsy between the ages of 4 to 10 . By the end of the study, 18 children were able to adapt to the KD. The Childhood Autism Rating Scale (CARS) was 
applied at the end of the diet process and it was reported that CARS scores increased significantly in 10 children with $\mathrm{ASD} .^{[47]}$ BTBR $\mathrm{T}+\mathrm{tf} / \mathrm{J}$ (BTBR) mice treated with $\mathrm{KD}$ also ameliorated typical ASD deficiencies related to myelin formation and white matter development/connectivity by affecting neurotransmitter signaling pathways, including glutamate, serotonin, neuronal nitric acid synthase and dopamine. ${ }^{[48]}$ In addition, BTBR mice were characterized by a different gut microbiota profile than controls. However, KD was thought to be associated with a higher risk of inflammatory and defective mitochondria. There are studies that it worsens side effects such as constipation and reflux. ${ }^{[49]}$ After the KD in mice with autism and epilepsy models, sociability was improved in female mice and repetitive behaviors were reduced, but behavioral improvements were more limited in males. ${ }^{[50]}$ In another study, children were administered $\mathrm{KD}$ to improve the autism behavior observed after $600 \mathrm{mg} / \mathrm{kg}$ of VPA administered to pregnant mice. Valproic acid offspring fed with KD showed improvements in social behavior compared to VPA offspring fed with standard diet. ${ }^{[51]}$ Ketogenic diet is a dietary treatment method that should be under the supervision of a pediatrician and a dietician as it is a difficult diet to follow and parents have problems in its implementation. Although there are studies in which KD therapy has positive effects on autism, more comprehensive studies are needed.

\section{PREBIOTICS AND PROBIOTICS - AUTISM}

Probiotics are non-pathogenic microorganisms living in the intestinal lumen, such as Lactobacillus, Lactococcus, Bifidobacteria, and Saccharomycetes that produce lactic acid. Probiotics possibly reduce gut inflammation through a variety of mechanisms, such as reducing gut barrier permeability, downregulation of inflammatory cytokines, and other immunomodulatory effects. Probiotics show therapeutic effects on the disturbed intestinal flora. Prebiotics reduced stress response in rodent and human studies. Its use in gastrointestinal diseases such as diarrhea, inflammatory bowel diseases and irritable bowel disease has been effective in reducing autism symptoms. ${ }^{[7]}$ In a study conducted in a maternal immune activation (MIA) model, orally administered Bacteroides fragilis $1 \times 10^{9}$ MIA enabled the offspring to develop autistic behavior. ${ }^{[52]}$ Maternal high-fat diet (mHFD) caused changes in the gut microbiome and social withdrawal in offspring. In particular, administration of Lactobacillus reuteri, not administering other strains of probiotics can reverse social behavior abnormalities except for repetitive behavior and anxiety. This again suggests the specificity of effects among probiotic strains. ${ }^{[53]}$

A study on hamsters in which autism-like behavior was induced by the administration of PPA or clindamycin examined the therapeutic effect of a three-week oral treatment with a mixture of Bifidobacteria and Lactobacilli strains. Clindamycin and PPA increased brain glutamate excitotoxicity in hamsters, causing $\mathrm{Mg}^{+}$and GABA depletion. According to previous studies on experimental animals, $\mathrm{Mg} 2^{+}$deficiency, which causes excessive $\mathrm{Ca}_{2}{ }^{+}$and glutamate, is among the causes of repetitive and impaired social behavior. Significant changes in oxidative stress markers, particularly glutathione and vitamin $\mathrm{C}$, were observed in the brains of hamsters in the PPA and clindamycin group.

All probiotic and prebiotic therapies were found to have curative effects, but lactobacillus had the strongest effect. ${ }^{[54]}$ In a randomized, double-blind, placebo-controlled study of 62 children with autism aged 3 to 16 years had Lactobacillus plantarum (daily dose, $\left.4.5 \times 10^{10} \mathrm{CFU}\right)$ administrated for three weeks. The children were divided into two groups: Group 1, a placebo during the first nutrition period ( 3 weeks) and probiotics during the second (3 weeks) and vice versa for Group 2. The behavioral/emotional impact of both dietary regimens (probiotic and placebo) was assessed by a standardized Developmental Behavior Checklist (DBC-P), but no significant difference was reported between the two groups. ${ }^{[55]}$ Additional study included 30 ASD patients with age of 5 to 9 years, who were given a fortified formula containing Lactobacillus acidophilus, Lactobacillus rhamnosus, and Bifidobacteria longum for three months and then evaluated through the Autism Treatment Evaluation Checklist (ATEC). Overall ATEC scores decreased significantly after probiotic treatment, and a significant reduction in the severity of autistic symptoms was reported in the speech/language/ 
communication categories of ATEC. ${ }^{[56]}$ A twocenter, randomized, placebo-controlled probiotic study was conducted in New Zealand in children followed up from birth to 11 years. Probiotics were administrated to mothers from 35 weeks of gestation to six months. Children were treated for up to two years from birth. Thus, worse behavior was observed with probiotics based on behavioral regulation and scores. ${ }^{[57]}$

In the reviewed studies, there is some evidence that prebiotic and probiotic applications improve the behavior of children with ASD. Probiotics have been observed to be beneficial in treating various psychological conditions such as depression and anxiety. The hypothesis behind these studies is that probiotics act through the gut-brain axis to affect neurotransmission and mood states. ${ }^{[53-58]}$ The system that provides communication between the gut and the brain is called the gut-brain axis. The task of this system is the secretion of specific enzymes according to the type of nutrient and the regulation of peristalsis. ${ }^{[58]}$ Probiotics can affect various neuroactive metabolites such as gamma-amino butyric acid (GABA) and serotonin. Serotonin has been observed to be influenced by the intestinal bacteria. There is a hyperactivation of a gene encoding serotonin reuptake transporters, particularly in individuals with ASD. Studies have linked neuropeptide oxytocin to social behavior and the pathogenesis of ASD. ${ }^{[3-58]}$ This may be the mechanism by which probiotics affect the behavior of ASD children. Research in this area is currently limited. According to studies on probiotic and prebiotic supplements, information is insufficient. Although probiotic and prebiotic supplements used as alternative treatments have been observed to provide substantial benefit, further designed, randomized, placebo-controlled clinical studies are needed to determine the appropriate strains, dosage and treatment timing.

\section{EFFECT OF FMT ON AUTISM}

Fecal microbiota transplantation has a 1700-year history. This forgotten treatment method has been put into use again in the last 50 years. The first known application of fecal material for treatment was made by a Chinese doctor Ge Hong in the fourth century. It has been used orally under the name of "yellow soup" in patients with severe diarrhea. There is no medical record of its use in the following centuries. It has been used orally and rectally in veterinary medicine since the $17^{\text {th }}$ century. Warm camel stool was used by German soldiers to treat bacterial dysentery during World War II. In 1958, FMT was first applied in modern medicine. Considering the connection between the gut and the brain, modulating the gut microbiome with antibiotics, probiotics, prebiotics, and FMT may be a viable therapeutic option. In FMT, a large number of common microbes from a healthy donor used to transform a dysbiotic gut microbiome into a healthy microbiome. Evidence-based criteria for standard application of FMT have not yet been defined. The donors should not have a history of antibiotic use, intravenous drug use, high risk sexual intercourse, tattoo or piercing, contagious, neoplastic, metabolic, allergic or autoimmune diseases in the last three months. Stool material should be at least 150 grams and should be obtained six hours before application. ${ }^{[59-61]}$ It was recommended to take a mild laxative such as magnesie calcinee the night before FMT was performed. One hour before FMT, two anti-diarrheal tablets of loperamide should be administrated to keep the transplanted stool in the intestines for a minimum of four hours. ${ }^{[62]}$ Stool can be diluted with water, salt water or milk. Then the stool suspension is obtained with a household hand mixer. It is passed through a gauze or coffee filter to remove solid particles. The resulting suspension is taken into $60 \mathrm{~mL}$ syringes. Stool suspension can be sent to the upper gastrointestinal tract via an esophagogastroduodenoscopy, nasojejunal tube, or nasogastric tube, and to the lower gastrointestinal tract with a colonoscopy or retention enema. ${ }^{[60,63]}$ One of the important questions is which way a stool suspension is administrated to the patient. The correct route of administration for gastrointestinal diseases in neuropsychiatric disorders is unknown. There are no clinical studies in which FMT is applied to autistic patients. However, studies have been performed on stool samples. Clostridium species have been found to be more in the stools of autistic children than healthy children. It was reported that the autistic symptoms of two children after FMT and the symptoms of five autistic children after the application of Bacteriodes produced in culture decreased. ${ }^{[12]}$ In a study conducted on 18 autistic children, each from a different family, for ASD treatment; colonic irrigation was 
performed with a two-week antibiotic treatment followed by a prolonged FMT with daily and lower maintenance doses for 7-8 weeks using the high starting dose. They found a significant reduction in GI symptoms at the end of treatment, including significant improvements in symptoms of constipation, diarrhea, indigestion, and abdominal pain. ${ }^{[64]}$ Although the roots of FMT at the past, there are limited studies in the literature. Fecal transplantation appears to be a promising method to remove dysbiosis in autism to reduce the effect of leaky gut flora on neuronal activities. It is certain that more detailed clinical studies are needed for it to be a relevant treatment method.

\section{DISCUSSION}

In this review article, the role of intestinal flora in autism and alternative treatment approaches as studies in the literature on dietary treatments, prebiotic-probiotic supplements and fecal transplantation were reviewed. Therefore, in autism, a behavioral disorder, the deterioration of the gut flora remains a matter of debate whether it is the cause or the result of autism. Treatment of the changing flora based on gastrointestinal disorders seen in almost all individuals with autism spectrum syndrome has significantly improved autism symptoms. Nutritional methods that are candidates for the treatment of these symptoms are approaches that should be considerate.

In conclusion, alternative diet approaches focus on improving the deteriorating microbiota. According to the studies, positive effects have been observed in alternative treatments. Since dietary treatments can be difficult to apply for individuals with autism, therapy should be applied with the support of an experienced dietitian and parents. Since casein and gluten can create morphine effect in autism, gluten-free and caseinfree diet can be applied in autism with individual approaches. It has been observed that the altered flora causes inflammation in the brain through the gut-brain axis. Therefore, the KD trials used in epilepsy for the treatment of inflammation were screened and positive findings were obtained. Although it is not certain, it is thought that KD, such as gluten-free-casein-free diet, can be applied as an alternative to dietician control with individual approaches in autism. Although comprehensive studies are needed on the application of probiotic and prebiotic supplements, the studies have a high beneficial effect and their applicability with appropriate approaches. There are not enough studies in the literature for fecal transplantation as another treatment approach. However, the studies observed showed a healing effect. It is currently not possible to say that any nutritional therapy and FMT are effective, as the studies conducted do not provide full effect in the treatment of autism. We believe that individual approaches are important in patients with autism spectrum diagnosis, and more comprehensive prospective studies are needed, since it is not clear that the dose and treatment period focused on improving the microbiota will be administered in the long term.

\section{Declaration of conflicting interests}

The authors declared no conflicts of interest with respect to the authorship and/or publication of this article.

\section{Funding}

The authors received no financial support for the research and/or authorship of this article.

\section{REFERENCES}

1. Aydın A, Kınacı C. Otizme çözüm var. 10. Baskı. İstanbul: Hayy Grup Yayıncllik; 2013.

2. Simonoff E, Pickles A, Charman T, Chandler S, Loucas T, Baird G. Psychiatric disorders in children with autism spectrum disorders: prevalence, comorbidity, and associated factors in a populationderived sample. J Am Acad Child Adolesc Psychiatry 2008;47:921-9.

3. Çalışkan Demir A, Özcan Ö. Otizm spektrum bozukluğu ve mikrobiyota. In: Ünal $\mathrm{S}$, editör. Mikrobiyota ve Psikiyatrik Hastalıklar. 1. Bask1. Ankara: Türkiye Klinikleri; 2020. s. 41- 7.

4. Allen-Brady K, Miller J, Matsunami N, Stevens J, Block $\mathrm{H}$, Farley $\mathrm{M}$, et al. A high-density SNP genomewide linkage scan in a large autism extended pedigree. Mol Psychiatry 2009;14:590-600.

5. Berding K, Donovan SM. Microbiome and nutrition in autism spectrum disorder: current knowledge and research needs. Nutr Rev 2016;74:723-36.

6. Dominguez-Bello MG, Costello EK, Contreras M, Magris M, Hidalgo G, Fierer N, et al. Delivery mode shapes the acquisition and structure of the initial microbiota across multiple body habitats in newborns. Proc Natl Acad Sci U S A 2010;107:11971-5.

7. Li Q, Zhou JM. The microbiota-gut-brain axis and its potential therapeutic role in autism spectrum disorder. Neuroscience 2016;324:131-9.

8. DiGiulio DB, Romero R, Amogan HP, Kusanovic JP, Bik EM, Gotsch F, et al. Microbial prevalence, diversity 
and abundance in amniotic fluid during preterm labor: a molecular and culture-based investigation. PLoS One 2008;3:e3056.

9. van De Sande MM, van Buul VJ, Brouns FJ. Autism and nutrition: the role of the gut-brain axis. Nutr Res Rev 2014;27:199-214.

10. Möhle L, Mattei D, Heimesaat MM, Bereswill S, Fischer A, Alutis M, et al. Ly6C(hi) Monocytes Provide a Link between Antibiotic-Induced Changes in Gut Microbiota and Adult Hippocampal Neurogenesis. Cell Rep 2016;15:1945-56.

11. Sandler RH, Finegold SM, Bolte ER, Buchanan CP, Maxwell AP, Väisänen ML, et al. Short-term benefit from oral vancomycin treatment of regressive-onset autism. J Child Neurol 2000;15:429-35.

12. Finegold SM, Molitoris D, Song Y, Liu C, Vaisanen ML, Bolte $\mathrm{E}$, et al. Gastrointestinal microflora studies in lateonset autism. Clin Infect Dis 2002;35(Suppl 1):S6-S16.

13. Holingue C, Newill C, Lee LC, Pasricha PJ, Daniele Fallin M. Gastrointestinal symptoms in autism spectrum disorder: A review of the literature on ascertainment and prevalence. Autism Res 2018;11:24-36.

14. Li $Q$, Han $Y$, Dy ABC, Hagerman RJ. The Gut Microbiota and Autism Spectrum Disorders. Front Cell Neurosci 2017;11:120.

15. Parracho HM, Bingham MO, Gibson GR, McCartney AL. Differences between the gut microflora of children with autistic spectrum disorders and that of healthy children. J Med Microbiol 2005;54:987-91.

16. Quigley EM. Leaky gut - concept or clinical entity? Curr Opin Gastroenterol 2016;32:74-9.

17. Wang X, Wang BR, Zhang XJ, Xu Z, Ding YQ, Ju G. Evidences for vagus nerve in maintenance of immune balance and transmission of immune information from gut to brain in STM-infected rats. World $\mathrm{J}$ Gastroenterol 2002;8:540-5.

18. Erickson CA, Stigler KA, Corkins MR, Posey DJ, Fitzgerald JF, McDougle CJ. Gastrointestinal factors in autistic disorder: a critical review. J Autism Dev Disord 2005;35:713-27.

19. Sharon G, Cruz NJ, Kang DW, Gandal MJ, Wang B, Kim YM, et al. Human Gut Microbiota from Autism Spectrum Disorder Promote Behavioral Symptoms in Mice. Cell 2019;177:1600-18.e17.

20. Bergdolt L, Dunaevsky A. Brain changes in a maternal immune activation model of neurodevelopmental brain disorders. Prog Neurobiol 2019;175:1-19.

21. El-Ansary A, Al-Ayadhi L. Relative abundance of short chain and polyunsaturated fatty acids in propionic acid-induced autistic features in rat pups as potential markers in autism. Lipids Health Dis 2014;13:140.

22. Liu F, Horton-Sparks K, Hull V, Li RW, MartínezCerdeño V. The valproic acid rat model of autism presents with gut bacterial dysbiosis similar to that in human autism. Mol Autism 2018;9:61.

23. Ersöz Alan B, Gülerman F. The role of gut microbiota in autism spectrum disorder. Turk Psikiyatri Derg 2019;30:210-9.
24. Olszak T, An D, Zeissig S, Vera MP, Richter J, Franke $\mathrm{A}$, et al. Microbial exposure during early life has persistent effects on natural killer $\mathrm{T}$ cell function. Science 2012;336:489-93.

25. Bilbo SD, Block CL, Bolton JL, Hanamsagar R, Tran PK. Beyond infection - Maternal immune activation by environmental factors, microglial development, and relevance for autism spectrum disorders. Exp Neurol 2018;299:241-51.

26. Cristiano C, Lama A, Lembo F, Mollica MP, Calignano A, Mattace Raso G. Interplay Between Peripheral and Central Inflammation in Autism Spectrum Disorders: Possible Nutritional and Therapeutic Strategies. Front Physiol 2018;9:184.

27. Krakowiak $\mathrm{P}$, Walker CK, Bremer AA, Baker AS, Ozonoff S, Hansen RL, et al. Maternal metabolic conditions and risk for autism and other neurodevelopmental disorders. Pediatrics 2012;129:e1121-8.

28. Doğan A, Yaşar S, Kayhan S, Kırmızıgöz Ş, Kaplan A. Bağırsak-beyin aksı. Türk Nöroşir Derg 2018;28:377-9.

29. Feliz B, Witt DR, Harris BT. Propionic acidemia: a neuropathology case report and review of prior cases. Arch Pathol Lab Med 2003;127:e325-8.

30. Breit S, Kupferberg A, Rogler G, Hasler G. Vagus nerve as modulator of the brain-gut axis in psychiatric and inflammatory disorders. Front Psychiatry 2018;9:44.

31. Artis D. Epithelial-cell recognition of commensal bacteria and maintenance of immune homeostasis in the gut. Nat Rev Immunol 2008;8:411-20.

32. Carabotti M, Scirocco A, Maselli MA, Severi C. The gut-brain axis: interactions between enteric microbiota, central and enteric nervous systems. Ann Gastroenterol 2015;28:203-9.

33. Ledford J, Gast DL. Feeding problems in children with autism spectrum disorders a review. Focus on Autism and Other Developmental Disabilities 2006;21:153-66.

34. Lyall K, Van de Water J, Ashwood P, Hertz-Picciotto I. Asthma and allergies in children with autism spectrum disorders: results from the CHARGE study. Autism Res 2015;8:567-74.

35. Gurney JG, McPheeters ML, Davis MM. Parental report of health conditions and health care use among children with and without autism: National Survey of Children's Health. Arch Pediatr Adolesc Med 2006; 160:825-30.

36. Postorino V, Sanges V, Giovagnoli G, Fatta LM, De Peppo L, Armando M, et al. Clinical differences in children with autism spectrum disorder with and without food selectivity. Appetite 2015;92:126-32.

37. Sharp WG, Jaquess DL, Lukens CT. Multi-method assessment of feeding problems among children with autism spectrum disorders. Research in Autism Spectrum Disorders 2013;7:56-65.

38. Curtin C, Anderson SE, Must A, Bandini L. The prevalence of obesity in children with autism: a secondary data analysis using nationally representative 
data from the National Survey of Children's Health. BMC Pediatr 2010;10:11.

39. Levy SE, Mandell DS, Merhar S, Ittenbach RF, PintoMartin JA. Use of complementary and alternative medicine among children recently diagnosed with autistic spectrum disorder. J Dev Behav Pediatr 2003;24:418-23.

40. Millward C, Ferriter M, Calver S, Connell-Jones G. Gluten- and casein-free diets for autistic spectrum disorder. Cochrane Database Syst Rev 2008;(2):CD003498.

41. Stewart PA, Hyman SL, Schmidt BL, Macklin EA, Reynolds A, Johnson CR, et al. Dietary supplementation in children with autism spectrum disorders: Common, insufficient, and excessive. J Acad Nutr Diet 2015;115:1237-48.

42. Srinivasan P. A review of dietary interventions in autism. Ann Clin Psychiatry 2009;21:237-47.

43. Ergin E. Peynir altı suyunda $\beta$-kazomorfin-7 ölçümü için elisaya dayalı kantitatif metot tasarımı. [Yüksek Lisans Tezi]. Kayseri: Erciyes Üniversitesi Tıp Fakültesi; 2013.

44. Marí-Bauset S, Zazpe I, Mari-Sanchis A, LlopisGonzález A, Morales-Suárez-Varela M. Evidence of the gluten-free and casein-free diet in autism spectrum disorders: a systematic review. J Child Neurol 2014;29:1718-27.

45. Elder JH. The gluten-free, casein-free diet in autism: an overview with clinical implications. Nutr Clin Pract 2008;23:583-8.

46. Hyman SL, Stewart PA, Foley J, Cain U, Peck R, Morris DD, et al. The gluten-free/casein-free diet: A double-blind challenge trial in children with autism. J Autism Dev Disord 2016;46:205-20.

47. Evangeliou A, Vlachonikolis I, Mihailidou H, Spilioti M, Skarpalezou A, Makaronas N, et al. Application of a ketogenic diet in children with autistic behavior: Pilot study. J Child Neurol 2003;18:113-8.

48. Mychasiuk R, Rho JM. Genetic modifications associated with ketogenic diet treatment in the BTBRT+Tf/J mouse model of autism spectrum disorder. Autism Res 2017;10:456-71.

49. Castro K, Faccioli LS, Baronio D, Gottfried C, Perry IS, dos Santos Riesgo R. Effect of a ketogenic diet on autism spectrum disorder: A systematic review. Research in Autism Spectrum Disorders 2015;20:31-8.

50. Ruskin DN, Fortin JA, Bisnauth SN, Masino SA. Ketogenic diets improve behaviors associated with autism spectrum disorder in a sex-specific manner in the EL mouse. Physiol Behav 2017;168:138-45.

51. Castro K, Baronio D, Perry IS, Riesgo RDS, Gottfried C. The effect of ketogenic diet in an animal model of autism induced by prenatal exposure to valproic acid. Nutr Neurosci 2017;20:343-50.
52. Hsiao EY, McBride SW, Hsien S, Sharon G, Hyde ER, McCue T, et al. Microbiota modulate behavioral and physiological abnormalities associated with neurodevelopmental disorders. Cell 2013;155:1451-63.

53. Buffington SA, Di Prisco GV, Auchtung TA, Ajami NJ, Petrosino JF, Costa-Mattioli M. Microbial Reconstitution Reverses Maternal Diet-Induced Social and Synaptic Deficits in Offspring. Cell 2016;165:1762-75.

54. Aabed K, Shafi Bhat R, Moubayed N, Al-Mutiri M, Al-Marshoud M, Al-Qahtani A, et al. Ameliorative effect of probiotics (Lactobacillus paracaseii and Protexin $\left.{ }^{\circledR}\right)$ and prebiotics (propolis and bee pollen) on clindamycin and propionic acid-induced oxidative stress and altered gut microbiota in a rodent model of autism. Cell Mol Biol (Noisy-le-grand) 2019;65:1-7.

55. Parracho HMRT, Gibson GR, Knott F, Bosscher D, Kleerebezem M, McCartney AL. A double-blind, placebo-controlled, crossover-designed probiotic feeding study in children diagnosed with autistic spectrum disorders. International Journal of Probiotics and Prebiotics 2010;5:69-74.

56. Shaaban SY, El Gendy YG, Mehanna NS, El-Senousy WM, El-Feki HSA, Saad $\mathrm{K}$, et al. The role of probiotics in children with autism spectrum disorder: A prospective, open-label study. Nutr Neurosci 2018;21:676-81.

57. Slykerman RF, Kang J, Van Zyl N, Barthow C, Wickens K, Stanley T, et al. Effect of early probiotic supplementation on childhood cognition, behaviour and mood a randomised, placebo-controlled trial. Acta Paediatr 2018;107:2172-8.

58. Erbaş O, Atasoy Ö, Ün M. Mikrobiyata davranışı nasıl etkiler?. Türkiye Klinikleri Psikiyatri-Özel Konular 2000;13:6-13.

59. Borody TJ, Warren EF, Leis SM, Surace R, Ashman O, Siarakas S. Bacteriotherapy using fecal flora: toying with human motions. J Clin Gastroenterol 2004;38:475-83.

60. Smits LP, Bouter KE, de Vos WM, Borody TJ, Nieuwdorp M. Therapeutic potential of fecal microbiota transplantation. Gastroenterology 2013;145:946-53.

61. Kang DW, Adams JB, Coleman DM, Pollard EL, Maldonado J, McDonough-Means S, et al. Long-term benefit of Microbiota Transfer Therapy on autism symptoms and gut microbiota. Sci Rep 2019;9:5821.

62. Demirci H, Uygun A. Fekal transplantasyon nasil ve kime uygulanmalı?. Güncel Gastroenteroloji, 2014;18:444-7.

63. Evrensel A, Ceylan ME. Psikiyatrik tedavide fekal mikrobiyota transplantasyonunun rolü. Anadolu J Psikiyatrisi 2015;16:380.

64. Kang DW, Adams JB, Gregory AC, Borody T, Chittick L, Fasano A, et al. Microbiota Transfer Therapy alters gut ecosystem and improves gastrointestinal and autism symptoms: an open-label study. Microbiome 2017;5:10. 